\title{
Upregulation of peroxisome proliferator-activated receptor gamma coactivator gene (PGC1A) during weight loss is related to insulin sensitivity but not to energy expenditure
}

\author{
G. Gastaldi • A. Russell • A. Golay • J.-P. Giacobino • \\ F. Habicht • V. Barthassat • P. Muzzin • \\ E. Bobbioni-Harsch
}

Received: 29 March 2007 / Accepted: 22 June 2007 / Published online: 8 September 2007

(C) Springer-Verlag 2007

\begin{abstract}
Aims/hypothesis We investigated whether skeletal muscle peroxisome proliferator-activated receptor gamma coactivator-1 (PGC1A; also known as PPARGC1A) and its target mitofusin-2 (MFN2), as well as carnitine palmitoyltransferase-1 (CPT1; also known as carnitine palmitoyltransferase 1A [liver] $[C P T 1 A])$ and uncoupling protein $(U C P) 3$, are involved in the improvement of insulin resistance and/or in the modification of energy expenditure during surgically induced massive weight loss.

Materials and methods Seventeen morbidly obese women (mean BMI: $45.9 \pm 4 \mathrm{~kg} / \mathrm{m}^{2}$ ) were investigated before, and 3 and 12 months after, Roux-en-Y gastric bypass (RYGB). We evaluated insulin sensitivity by the euglycaemic-hyperinsulinaemic clamp, energy expenditure and substrate oxidation
\end{abstract}

G. Gastaldi and A. Russell share first authorship.

G. Gastaldi · A. Golay · F. Habicht • V. Barthassat •

E. Bobbioni-Harsch $(\square)$

Service of Therapeutic Education for Chronic Diseases,

Geneva University Hospital,

24, Rue Micheli du Crest,

1211 Geneva, Switzerland

e-mail: Elisabetta.Harsch@hcuge.ch

\section{A. Russell}

Center for Physical Activity and Nutrition (C-PAN),

School of Exercise and Nutrition Sciences,

Deakin University,

Melbourne, VIC, Australia

J.-P. Giacobino $\cdot$ P. Muzzin

Department of Cell Physiology and Metabolism,

Geneva Medical School,

Geneva, Switzerland by indirect calorimetry, and muscle mRNA expression by PCR.

Results Post-operatively, $P G C 1 A$ was enhanced at $3(p=$ $0.02)$ and 12 months $(p=0.03)$ as was MFN2 $(p=0.008$ and $p=0.03$ at 3 and 12 months respectively), whereas UCP3 was reduced $(p=0.03)$ at 12 months. CPT1 did not change. The expression of $P G C 1 A$ and MFN2 were strongly $(p<$ $0.0001)$ related. Insulin sensitivity, which increased after surgery ( $p=0.002$ at $3, p=0.003$ at 12 months), was significantly related to $P G C 1 A$ and $M F N 2$, but only $M F N 2$ showed an independent influence in a multiple regression analysis. Energy expenditure was reduced at 3 months postoperatively ( $p=0.001$ vs before $\mathrm{RYGB})$, remaining unchanged thereafter until 12 months. CPT1 and UCP3 were not significantly related to the modifications of energy expenditure or of lipid oxidation rate.

Conclusions/interpretation Weight loss upregulates $P G C 1 A$, which in turn stimulates $M F N 2$ expression. MFN2 expression significantly and independently contributes to the improvement of insulin sensitivity. UCP3 and CPT1 do not seem to influence energy expenditure after RYGB.

Keywords $C P T 1 \cdot$ Insulin sensitivity $\cdot M F N 2 \cdot P G C 1 A$. $P P A R G C 1 A \cdot$ Roux-en-Y gastric bypass ·

UCP3 · Weight loss

$\begin{array}{ll}\text { Abbreviations } \\ \text { CPT1 } & \text { carnitine palmitoyltransferase-1 } \\ \text { LBM } & \text { lean body mass } \\ \text { MFN2 } & \text { mitofusin-2 } \\ \text { PGC1A } & \begin{array}{l}\text { peroxisome proliferator-activated receptor } \\ \text { gamma coactivator-1 }\end{array}\end{array}$


RER respiratory exchange rate

RYGB Roux-en-Y gastric bypass

UCP uncoupling protein

$\dot{V} \mathrm{O}_{2} \quad$ oxygen consumption

$\dot{V} \mathrm{CO}_{2} \quad$ carbon dioxide production

\section{Introduction}

Skeletal muscle mitochondrial function is impaired in obese and in diabetic patients [1], and this may contribute to the development of insulin resistance [2]. In turn, insulin resistance contributes to obesity-related co-morbidities, such as type 2 diabetes and cardiovascular diseases [3]. Thus, the correction of excess body weight and insulin resistance is of primary importance in the prevention of pathologies linked to obesity.

Bariatric surgery is the elective treatment for morbid obesity, with Roux-en-Y gastric bypass (RYGB) accounting for more than $80 \%$ of all bariatric interventions [4]. It induces a large and durable weight reduction as well as a substantial amelioration of insulin resistance [5].

Despite the large number of RYGB operations performed, the metabolic and molecular determinants of improved insulin sensitivity and of body weight loss are not well known.

Among the numerous candidates potentially involved in the amelioration of insulin sensitivity, we focused on the peroxisome proliferator activated receptor gamma-coactivator-1 (PGC1A) and some of its known transcriptional targets.

PGC1A and its target mitofusin-2 (MFN2) are both involved in mitochondrial biogenesis and in the maintenance of the mitochondrial network [6-8]. Moreover, MFN2 augments mitochondrial oxidative capacity for both glucose and lipids [9] and PGC1A increases expression of the insulinsensitive glucose transporter 4 [10]. Thus, PGC1A and MFN2 could both enhance insulin sensitivity.

PGC1A and MFN2 are altered in patients with obesity and type 2 diabetes [11, 12], conditions that are both characterised by intense insulin resistance. On the other hand, these factors are upregulated by physical exercise [7, 13], a situation which is known to ameliorate insulin sensitivity [14]. It is therefore reasonable to hypothesise that PGC1A and MFN2 could be involved in the improvement of insulin sensitivity induced by weight loss.

Another PGC1A target is carnitine palmitoyltransferase-1 (CPT1) [15], the main regulator of long-chain fatty acids transport across the mitochondrial membrane [16]. A defect in CPT1 has been observed in muscle of obese persons [17], persisting after weight loss [18]. Defective lipid oxidation, resulting from impaired CPT1 activity, could lead to excessive intramyocellular triacylglycerol accumulation and, ul- timately, to insulin resistance [17]. Furthermore, after weight loss, a low lipid oxidation rate could favour relapse to obesity [18].

We have previously demonstrated that during RYGBinduced weight loss an energy economy mechanism, based on low lipid oxidation, hampers the process of body weight loss [19]. Thus, we hypothesised that a defect in CPT1 could influence energy expenditure and/or lipid oxidation after RYGB.

The uncoupling protein (UCP) family is a group of proteins that contribute to the regulation of lipid oxidation [20]. Therefore, UCPs could play an important role in the regulation of energy expenditure [21]. We previously demonstrated that, when body weight is stable, UCP3 expression in the skeletal muscle of obese participants is not significantly related to the basal metabolic rate [22]. However, the decreased $U C P 3$ expression repeatedly reported in post-obese patients [23-25] suggests that, during the weight loss process, downregulation of $U C P 3$ could lead to energy conservation, thus limiting the extent of weight loss. Therefore, UCP3 is a potential determinant of energy expenditure during weight loss.

In the present study, we studied the change in skeletal muscle expression of PGC1A (also known as PPA$R G C 1 A$ ), $M F N 2, C P T 1$ (also known as carnitine palmitoyltransferase 1A [liver] [CPT1A]) and UCP3 during surgically induced massive weight loss. Our aim was to investigate whether one or more of these factors are involved in the improvement of insulin sensitivity and/or in the modifications of energy expenditure associated with surgically induced weight loss. Two post-operative time-points, 3 and 12 months, were selected because they are representative of the rapid and slow phases of body weight loss induced by RYGB, as previously described [26].

\section{Materials and methods}

Participants A group of 17 morbidly obese normotensive women (mean age $39 \pm 11$ years) participated in the study. Ten of these had normal fasting plasma glucose (i.e. $<6.0 \mathrm{mmol} / \mathrm{l}$ ), four impaired fasting glucose (i.e. 6.0 $6.9 \mathrm{mmol} / \mathrm{l}$ ) and three had type 2 diabetes (i.e. fasting plasma glucose $\geq 7 \mathrm{mmol} / \mathrm{l}$ ) not treated with insulin. The participants were studied before and 3 months after RYGB. Eleven of the participants also agreed to undergo the same tests 12 months after the operation. At this last time-point, the euglycaemic-hyperinsulinaemic clamp was not done in one patient for technical reasons. This study was approved by the Ethical Committee of the Department of Surgery of the Geneva University Hospital. The patients were in- 
formed about the aims of the study and gave their written consent.

Surgical procedure RYGB is a surgical procedure whereby a small stomach pouch is first separated from the distal stomach. Following this, a Y-shaped section of the small intestine is connected to the gastric pouch in order to bypass the duodenum and a part of the jejunum. Finally, this bypassed portion of the intestine is attached more distally to the small bowel [27]. This surgical procedure induces weight loss by both a restrictive (i.e. stomach volume reduction) and a malabsorptive (i.e. the bypass of the duodenum and a part of the jejunum) mechanism.

Experimental protocol The patients were admitted to hospital in the morning (08:00 hours), after an overnight fasting period (10-12 h). First, body weight, height and body composition were measured. After voiding, venous catheters were inserted into a dorsal vein of the hand and into the left antecubital vein of the contra-lateral arm (for blood sampling and infusion of all test substances respectively). Indirect calorimetry was performed for $30 \mathrm{~min}$ in basal fasting conditions and repeated throughout the last $30 \mathrm{~min}$ of the euglycaemic-hyperinsulinaemic clamp. After the first calorimetric measurement, a skeletal muscle sample was taken for biopsy; then the patient underwent a $2 \mathrm{~h}$ euglycaemic-hyperinsulinaemic clamp. At the end of the tests urine was collected in order to measure urinary nitrogen.

Anthropometric measurements Body weight was measured using a Lindel balance scale (Samhald, Klippan, Sweden) while the participant wore only underclothes and no shoes. Height was measured at the same time. Body composition was measured using a body impedance analyser (Nutriguard-M, Darmstadt, Germany), with the electrodes placed on the right hand and foot. Lean body mass (LBM) was calculated according to Segal [28].

Indirect calorimetry For this test, patients were asked not to perform intense physical activity for $48 \mathrm{~h}$ before the test and also to avoid smoking. For the 3 days preceding the test, they were also advised to consume a balanced diet, consisting of about $40 \%$ of energy as carbohydrate, $30 \%$ as lipid and $30 \%$ as protein, without any modification of their usual energy intake. The patients were placed in a recumbent position with the head in a ventilated hood (Deltatrac; Datex, Helsinki, Finland) and oxygen consumption $\left(\dot{V} \mathrm{O}_{2}\right)$ and carbon dioxide production $\left(\dot{V} \mathrm{CO}_{2}\right)$ were measured. After a 15 min equilibration period, gas exchange was measured for $30 \mathrm{~min}$ and used to calculate the respiratory quotient as well as glucose and lipid oxidation rates, according to Ferrannini [29]. Protein oxidation was calculated as $6.235 \times N$ [30], where $N$ is nitrogen excretion $(\mathrm{mg} / \mathrm{min})$ in urine measured by spectrophotometry. The lipid and protein oxidation rates are expressed as $\mathrm{mg} \mathrm{kg} \mathrm{LBM}{ }^{-1} \mathrm{~min}^{-1}$. Glucose oxidation is ex-

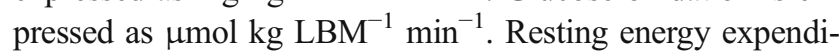
ture was calculated from the rates of substrate oxidation and expressed in $\mathrm{MJ} / \mathrm{day}$. The respiratory exchange rate (RER) was calculated as the ratio between $\dot{V} \mathrm{CO}_{2}$ and $\dot{V} \mathrm{O}_{2}$.

Euglycaemic-hyperinsulinaemic clamp procedure Insulin sensitivity was evaluated by the euglycaemic-hyperinsulinaemic clamp procedure [31]. After a priming dose $\left(0.8 \mathrm{U} / \mathrm{m}^{2}\right.$ of body surface area over $10 \mathrm{~min}$ ), the patients received a constant infusion of insulin at the rate of $0.04 \mathrm{U} \mathrm{m}^{-2} \mathrm{~min}^{-1}$ throughout the test. The overall duration of the test was $120 \mathrm{~min}$. A $200 \mathrm{~g} / \mathrm{l}$ glucose solution was infused at variable rates in order to maintain glycaemia at a constant level of $5.0 \mathrm{mmol} / 1$. Whole-body glucose uptake, expressed in $\mu \mathrm{mol}$ $\mathrm{kg} \mathrm{LBM}{ }^{-1} \mathrm{~min}^{-1}$, was calculated during the last $40 \mathrm{~min}$ period of the test, when glucose infusion reached steady state. The insulin-induced modifications of substrate oxidative rate were calculated as the differences between the values measured during the clamp and those measured in basal conditions ( $\Delta$ from baseline).

Blood chemistry Plasma glucose was determined enzymatically using an automated glucose analyser (Beckman Coulter, Fullerton, CA, USA). Insulin concentrations were measured by radioimmunoassay, using a commercial kit (Linco Research, St Charles, MI, USA).

Muscle biopsy sampling, treatment and analysis Skeletal muscle samples were obtained under local anaesthesia from the belly of the vastus lateralis muscle using a percutaneous needle biopsy technique modified to include suction. A single incision was made in the skin and two muscle samples were taken from a single insertion of the biopsy needle. After the first biopsy cut, the needle was rotated and a second cut was performed. Each muscle sample weighed between 50 and $80 \mathrm{mg}$. The muscle sample was immediately frozen in liquid nitrogen and used for RNA extraction.

RNA extraction from muscle biopsies and real-time quantitative PCR Total RNA was extracted from $\sim 40 \mathrm{mg}$ frozen muscle portions by the guanidinium isothiocyanate acid phenol procedure, after which $3 \mu \mathrm{g}$ of RNA was reversetranscribed to cDNA as reported previously [32]. Quantitative PCR was performed using a thermal cycler system (MX3000p; Roche Diagnostics, Rotkreuz, Switzerland) with gene-specific primers as reported previously [32]. To control for any variations due to efficiencies of the reverse transcription and PCR, ribosomal $28 \mathrm{~S}$ was used as an internal control. Leptin mRNA was also measured in the 
Table 1 Profile of several anthropometric and metabolic parameters, measured in morbidly obese women during the body weight loss process induced by RYGB

Pre-operative values of the 11 patients (out of 17) tested at 12 months are reported in parentheses

${ }^{\mathrm{a}} p<0.05$ to $p<0.01$

${ }^{\mathrm{b}} p<0.005$ to $p<0.001$

${ }^{\mathrm{c}} p<0.0005$ to $p<0.0001$ for difference from pre-operative values

\begin{tabular}{|c|c|c|c|}
\hline & Before RYGB $(n=17)$ & 3 months $(n=17)$ & $\begin{array}{l}12 \text { months } \\
(n=11)\end{array}$ \\
\hline Body weight (kg) & $124.4 \pm 13(127.8 \pm 12)$ & $102.2 \pm 12^{\mathrm{c}}$ & $82.5 \pm 13^{c}$ \\
\hline BMI $\left(\mathrm{kg} / \mathrm{m}^{2}\right)$ & $45.9 \pm 4(46.1 \pm 3)$ & $37.7 \pm 4^{\mathrm{c}}$ & $30.5 \pm 5^{\mathrm{c}}$ \\
\hline Plasma glucose $(\mathrm{mmol} / \mathrm{l})$ & $5.8 \pm 1.1(5.9 \pm 1.2)$ & $4.9 \pm 0.4^{\mathrm{a}}$ & $4.5 \pm 0.4^{\mathrm{a}}$ \\
\hline Plasma insulin (pmol/l) & $168.6 \pm 86(170.3 \pm 86)$ & $84.3 \pm 34^{\mathrm{c}}$ & $56.8 \pm 34^{\mathrm{b}}$ \\
\hline Energy expenditure (MJ/day) & $8.28 \pm 0.4(8.10 \pm 0.7)$ & $6.80 \pm 0.8^{\mathrm{b}}$ & $6.90 \pm 0.9^{\mathrm{b}}$ \\
\hline $\begin{array}{l}\text { Protein oxidation } \\
\left(\mathrm{mg} \mathrm{kg} \mathrm{LMB}{ }^{-1} \min ^{-1}\right)\end{array}$ & $0.79 \pm 0.3(0.84 \pm 0.2)$ & $0.46 \pm 0.13^{\mathrm{b}}$ & $0.74 \pm 0.3$ \\
\hline $\begin{array}{l}\text { Glucose oxidation } \\
\left(\mu \mathrm{mol} \mathrm{kg} \mathrm{LMB}{ }^{-1} \min ^{-1}\right)\end{array}$ & $5.25 \pm 4.4(5.45 \pm 2.8)$ & $1.93 \pm 4.4$ & $1.54 \pm 4.9^{\mathrm{a}}$ \\
\hline $\begin{array}{l}\text { Lipid oxidation } \\
\left(\mathrm{mg} \mathrm{kg} \mathrm{LMB}^{-1} \mathrm{~min}^{-1}\right)\end{array}$ & $1.66 \pm 0.5(1.52 \pm 0.3)$ & $1.88 \pm 0.5$ & $1.98 \pm 0.3$ \\
\hline
\end{tabular}

muscle samples to control for any potential contamination by fat tissue in the biopsies. All PCR runs were performed in triplicate.

Statistics Values are given as means \pm SD. The non-parametric Wilcoxon signed-rank test was used for comparisons before and after RYGB. Since at 12 months 11 patients were investigated, of whom only ten could perform the euglycaemic clamp, the Wilcoxon test was applied to the 11 pairs of values for mRNA expression and to the ten pairs of values for the glucose uptake. Simple and multiple regression analyses were used to examine associations and to identify the best predictors of the investigated variables. The threshold of significance was set at $p<0.05$. Statistical analyses were performed by a computerised program (Statview 4; Abacus Concepts, Berkeley, CA, USA).

\section{Results}

The change in body weight and BMI is illustrated in Table 1, as well as the significant decrease of fasting glucose and insulin plasma levels.

Energy expenditure (MJ/day) was reduced at 3 months and remained so at 12 months (Table 1). Protein oxidation was decreased 3 months $(p=0.001)$ after surgery, returning to pre-operative values at 12 months. Fasting glucose oxidation was not statistically significantly reduced at 3 months $(p=0.08)$, but the reduction reached statistical significance at 12 months $(p<0.05)$. Lipid oxidation was not significantly changed after surgery.

Figure 1a shows that skeletal muscle $P G C 1 A$ mRNA was increased both at 3 and 12 months compared with preoperative values ( $p=0.02$ and $p=0.03$, respectively). Muscle MFN2 mRNA (Fig. 1b) was also increased $(p=0.008$ at 3 months, $p=0.03$ at 12 months after surgery). There was no significant modification of CPT1 mRNA levels (Fig. 1c) following RYGB. UCP3 mRNA levels (Fig. 1d) were decreased 12 months after surgery $(p=0.03)$.

Simple regression analysis revealed a significant positive relationship between $P G C 1 A$ and MFN2 $(p<0.0001$, $r^{2}=0.53$ ), as shown in Fig. 2. No significant relationship linked $C P T 1$ or $U C P 3$ to $P G C 1 A$. UCP3 was positively linked to BMI $\left(p=0.001, r^{2}=0.22\right)$.

As shown in Fig. 3a, whole-body glucose uptake, assessed by the clamp technique, was increased at 3 and 12 months ( $p=0.002$ and $p=0.003$ vs pre-op respectively). During the test, both insulin-stimulated non-oxidative (Fig. 3b) and oxidative (Fig. 3c) glucose utilisation, expressed as $\Delta$ from baseline, were higher both at 3 and 12 months than preoperative values $(p=0.01$ at 3 months and $p=0.006$ at
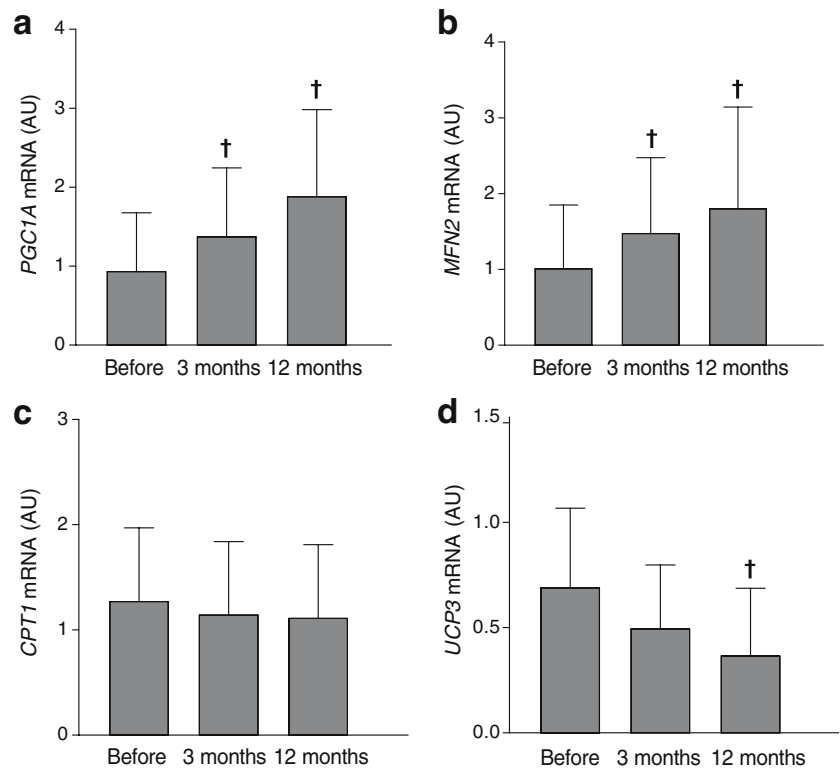

Fig. 1 Modifications of skeletal muscle PGC1A (a), MFN2 (b), CPT1 (c) and $U C P 3$ (d) expression during RYGB-induced weight loss. The pre-operative values (arbitrary units [AU]) of the 11 patients (out of 17) tested at 12 months were: $P G C 1 A 1.16 \pm 0.8 ; M F N 21.24 \pm 0.9$; $C P T 1115 \pm 0.8$; UCP3 $0.68 \pm 0.4$. $\dagger p<0.05$ to $p<0.01$ vs pre-operative values 


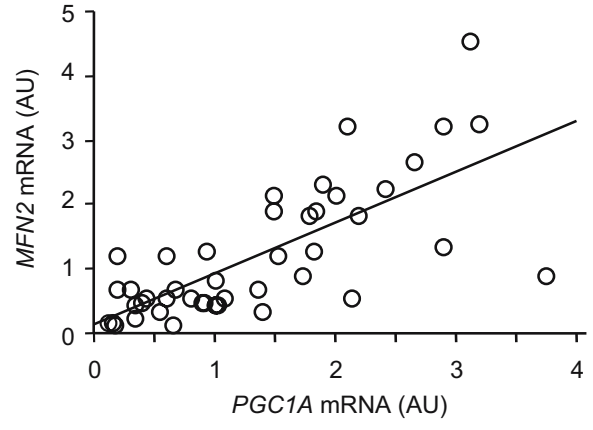

Fig. 2 Relationship between $P G C 1 A$ and $M F N 2$ mRNA expression during RYGB-induced weight loss. $p<0.0001, r^{2}=0.53$

12 months for non-oxidative glucose utilisation; $p=0.04$ at 3 months and $p=0.02$ at 12 months for oxidative glucose utilisation). The inhibition of lipid oxidation was more marked after surgery ( $p=0.03$ and $p=0.002$, respectively at 3 and 12 months; Fig. 3d). During the steady state of the clamp, the RER varied consistently with these modifications (Table 2). In fact, at all the time-points, euglycaemic hyperinsulinaemia induced an increase in RER. This increase, however, was more marked both at 3 and 12 months than in the pre-operative conditions ( $p=0.01$ and $p=0.002$, respectively).

Table 3 illustrates the variables that, in simple regression analysis, showed a significant relationship with glucose uptake, which was positively related to both $P G C 1 A(p=0.005)$ and MFN2 ( $p=0.0001)$ mRNA expression, whereas BMI $(p=0.0001)$ and UCP3 $(p=0.03)$ showed a negative relationship with glucose uptake. CPT1 mRNA was not related to glucose uptake.

Multiple regression analysis (Table 4) showed that the relationship between both $P G C 1 A$ and $U C P 3$ and glucose uptake was no longer statistically significant when $M F N 2$ and BMI were taken into account. Therefore, MFN2 and BMI remained the significant and independent determinants of glucose uptake $\left(r^{2}=0.48\right)$.

MFN2 mRNA was related to the glucose oxidation rate measured during the clamp $\left(p=0.008 ; r^{2}=0.16\right)$. $C P T 1$ and $U C P 3$ were not related to energy expenditure or to fasting lipid oxidation.

\section{Discussion}

The main results of this investigation are that, in muscle, weight reduction upregulates expression of $P G C 1 A$ (Fig. 1). Second, this upregulation is associated with increased expression of MFN2, which, in turn, may contribute to the improvement of insulin sensitivity.

To our knowledge, this is the first report demonstrating that, during weight reduction, muscle $P G C 1 A$ is upregu- lated and that this upregulation is strongly linked to the increase in MFN2 mRNA expression.

In fact, an increase in skeletal muscle $P G C 1 A$ and $M F N 2$ in response to physical exercise has already been recognised [7]. Here, we demonstrate that both PGC1A and MFN2 are upregulated by weight reduction and that the modifications of PGC1A account for over $50 \%$ of those of MFN2 (Fig. 2). We therefore suggest that, during body weight loss, the upregulation of $P G C 1 A$ induces increased expression of $M F N 2$, similarly to the situation during physical exercise.

After surgery, insulin sensitivity improves, as documented by the increase of glucose uptake and the inhibition of lipid oxidation during the clamp tests (Fig. 3). Consistent with these modifications, the RER was more markedly increased during the steady state of the clamp at both post-operative time points (Table 2). This improvement was independently influenced by both BMI and MFN2 expression, which together accounted for about $50 \%$ of the modifications of insulin sensitivity (Table 4). Similarly to our results, MFN2 was seen to be increased after massive weight loss induced by another bariatric procedure, the biliopancreatic diversion [33]. Interestingly, weight reduction obtained by this surgical intervention is mainly based on malabsorption, namely of fat. In contrast, RYGB leads to a reduced food intake, with a particular restriction of carbohydrate [34], as strongly indicated in our results by the low post-operative basal glucose oxidation rate (Table 1). This suggests that diet composition does not play a role in the stimulation of MFN2.

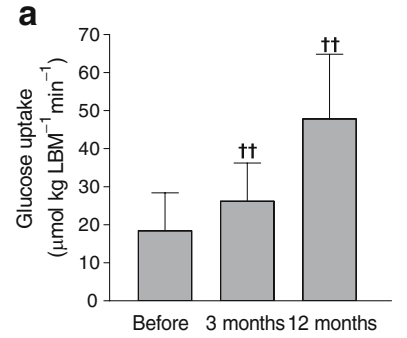

b
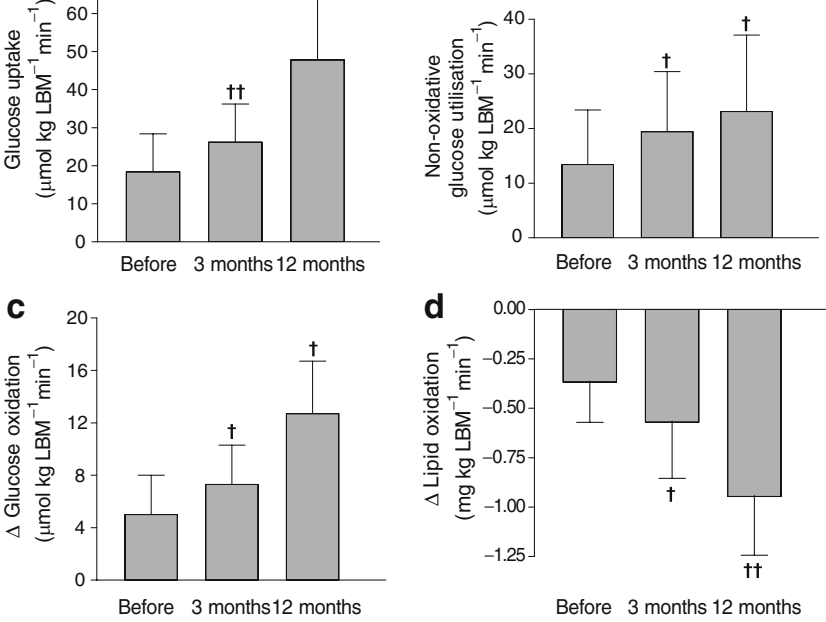

Fig. 3 Glucose uptake (a), non-oxidative glucose utilisation (b), glucose oxidation (c) and lipid oxidation (d) during hyperglycaemichyperinsulinaemic clamp. Glucose and lipid oxidation were calculated as $\Delta$ from basal conditions, before and after RYGB gastric bypass. The pre-operative values of the ten patients (out of 17) submitted to the clamp test at 12 months were: glucose uptake $20.7 \pm 11.6 \mu \mathrm{mol} \mathrm{kg}$ $\mathrm{LBM}^{-1} \mathrm{~min}^{-1}$; non-oxidative glucose utilisation $15.3 \pm 11.6 \mu \mathrm{mol} \mathrm{kg}$ $\mathrm{LBM}^{-1} \mathrm{~min}^{-1} ; \Delta$ glucose oxidation $5.8 \pm 7.2 \mu \mathrm{mol} \mathrm{kg} \mathrm{LBM}{ }^{-1} \mathrm{~min}^{-1}$; $\Delta$ lipid oxidation $-0.35 \pm 0.2 \mathrm{mg} \mathrm{kg} \mathrm{LBM}{ }^{-1} \min ^{-1}$. $\dagger p<0.05$ to $p<$ $0.01, \dagger \uparrow p<0.005$ to $p<0.001$ vs pre-operative values 
Table 2 Variations of the respiratory exchange rate, measured in fasting conditions and during the steady state of the euglycaemichyperinsulinaemic clamp

\begin{tabular}{lcll}
\hline & Before RYGB & $\begin{array}{l}3 \text { months after } \\
\text { RYGB }\end{array}$ & $\begin{array}{l}12 \text { months after } \\
\text { RYGB }\end{array}$ \\
\hline Fasting & $\begin{array}{c}0.78 \pm 0.05 \\
(0.78 \pm 0.06)\end{array}$ & $0.75 \pm 0.04$ & $0.75 \pm 0.04$ \\
Clamp & $\begin{array}{c}0.82 \pm 0.05 \\
(0.81 \pm 0.05)\end{array}$ & $0.82 \pm 0.06$ & $0.86 \pm 0.06$ \\
$\Delta$ & $\begin{array}{c}0.04 \pm 0.03 \\
(0.03 \pm 0.03)\end{array}$ & $0.07 \pm 0.04^{\mathrm{a}}$ & $0.11 \pm 0.04^{\mathrm{b}}$ \\
& & \\
\hline
\end{tabular}

Pre-operative values of the 11 patients (out of 17) tested at 12 months are reported in parentheses

${ }^{\text {a }} p<0.05$ to $p<0.01$

${ }^{\mathrm{b}} p<0.005$ to $p<0.001$ for difference from pre-operative values

Three months after the operation, protein oxidation was markedly decreased. This result is in keeping with the previously reported reduction of protein utilisation during severe restriction of energy intake [35].

In our study, we did not observe any significant modification of CPT1 mRNA expression. This is in agreement with previously reported findings $[18,36]$ after moderate weight loss, demonstrating that even massive weight reduction is without effect on $C P T 1$ expression. In contrast to physical exercise-mediated $P G C 1 A$ upregulation, $P G C 1 A$ upregulation due to weight reduction was not associated with an increase of $C P T 1$ expression. The lack of $C P T 1$ induction could be explained by the fact that $P G C 1 A$ requires the intervention of other co-factors in order to increase mRNA expression of its targets. These co-factors may be stimulated (or not) according to specific physiopathological situations and/or the tissues in question. For instance, liver PGC1A enhances the stimulatory action of thyroid hormone on $C P T 1$ [37]. If the same mechanism regulates muscle $C P T 1$, the well documented decrease of thyroid function during active weight loss process [38] could conceivably prevent an increase of $C P T 1$ expression.

The second aim of the present study was to investigate whether $C P T 1$ and/or $U C P 3$ are involved in the modifica-

Table 3 Synthesis of simple regression analyses of BMI and muscle molecular parameters vs insulin sensitivity measured before and during RYGB-induced weight loss

\begin{tabular}{lll}
\hline Independent variable & \multicolumn{2}{l}{ Dependent variable } \\
\cline { 2 - 3 } & \multicolumn{2}{l}{ Glucose uptake } \\
\cline { 2 - 3 } & $p$ value & $r^{2}$ \\
\hline PGC1A & 0.005 & 0.17 \\
MFN2 & 0.0001 & 0.29 \\
UCP3 & 0.03 & -0.10 \\
BMI & 0.0001 & -0.29 \\
\hline
\end{tabular}

Table 4 Multiple regression analysis of factors influencing insulin sensitivity, i.e. glucose uptake

\begin{tabular}{lll}
\hline Independent variable & \multicolumn{2}{l}{ Dependent variable } \\
\cline { 2 - 3 } & \multicolumn{2}{l}{ Glucose uptake } \\
\cline { 2 - 3 } & $p$ value & $R^{2}$ \\
\hline PGC1A & $\mathrm{NS}$ & 0.48 \\
MFN2 & 0.006 & 0.48 \\
UCP3 & $\mathrm{NS}$ & 0.48 \\
BMI & 0.002 & 0.48 \\
\hline
\end{tabular}

There was a significant and independent relationship of BMI ( $p=$ $0.002)$ and MFN2 $(p=0.006)$ with insulin sensitivity measured in morbidly obese women before and during RYGB-induced weight loss

tions of energy expenditure and whole-body lipid oxidation during weight reduction induced by gastric bypass.

As previously reported by our group, the massive weight loss process following RYGB is accompanied by an energy economy phenomenon, essentially due to a defect in lipid oxidation. This phenomenon can impair the correction of excess body weight [19].

In muscle, both $C P T 1$ and $U C P 3$ contribute to the control of lipid oxidation. Their downregulation, after weight reduction, has been proposed as a possible reason for limited weight loss and/or relapse to obesity [18, 23]. Skeletal muscle is a major contributor to overall energy expenditure. Therefore, it was logical to expect that the modifications of $C P T 1$ and/or UCP3 could, at least in part, explain those of wholebody energy expenditure.

Contrary to this hypothesis, $C P T 1$ and $U C P 3$ mRNA expression did not show any significant relationship with post-operative energy expenditure or lipid oxidation. The biological activity of these factors was not measured in the present study. We cannot, therefore, rule out the possibility that muscle $C P T 1$ and $U C P 3$ have an impact on overall energy balance during weight loss. Two points, however, should be considered: first, the studies in which both mRNA expression and activity were measured demonstrate that in general these two parameters consistently vary [39]. Second, and even more convincingly, the only study investigating $C P T 1$ activity and energy expenditure, both at the muscle level, failed to find any relationship between $C P T 1$ activity and energy expenditure, even when the latter is measured locally [40].

A recent hypothesis on the physiological role of $U C P 3$ could help interpret the decrease in $U C P 3$ expression during weight loss [41]. In fact, based on in vitro experiments, $U C P 3$ has been proposed to be a factor that limits reactive oxygen species (ROS) production by facilitating fatty acid oxidation [41]. Thus, the role of UCP3 would be to protect muscle tissue against lipotoxicity, rather than to regulate energy expenditure. Schrauwen et al. [42] have suggested 
that UCP3 could contribute to outward translocation of NEFA, occurring when NEFA availability exceeds mitochondrial oxidative capacity. This mechanism would protect the mitochondria from NEFA accumulation. According to this hypothesis, the UCP3 downregulation after weight loss could result from a reduced need for NEFA exportation from the mitochondrial matrix. Finally, UCP3 expression is powerfully regulated by intramyocellular triacylglycerol content [24]. Therefore, the decrease in UCP3 expression with decreasing BMI could be due to muscular triacylglycerol depletion and to the reduced lipotoxicity resulting from that depletion.

In conclusion, our study shows that massive weight loss upregulates $P G C 1 A$ mRNA expression in skeletal muscle. This increase is associated with enhanced MFN2 expression, which contributes to the amelioration of insulin sensitivity. CPT1 or UCP3 mRNA expression does not show any significant impact on the modifications of insulin sensitivity or on the regulation of energy expenditure.

Further studies are needed to identify co-factors that have a permissive role for $P G C 1 A$ in the stimulation of its targets and to determine whether these co-factors are specifically activated in different physiopathological conditions.

Acknowledgements G. Gastaldi was supported by grants from the Barbour Foundation, the Ousseimi Foundation and the Fond pour l'encouragement de la recherche sur la nutrition en Suisse. This work was supported by the Swiss National Science Foundation grant no. 3200-061339.

Duality of interest The authors declare that there is no duality of interest associated with this manuscript.

\section{References}

1. Stump C, Henriksen E, Wei Y, Sowers J (2006) The metabolic syndrome: role of skeletal muscle metabolism. Ann Med 38:389-402

2. Morino K, Petersen KF, Shulman G (2006) Molecular mechanisms of insulin resistance in humans and their potential links with mitochondrial dysfunction. Diabetes 55:S9-S15

3. Muoio DM, Newgard CB (2006) Obesity-related derangements in metabolic regulation. Annu Rev Biochem 75:367-401

4. Santry HP, Gillen DL, Lauderdale DS (2005) Trends in bariatric surgical procedures. JAMA 294:1909-1917

5. Pereira J, Lazarin M, Pareja J, de Souza A, Muscelli E (2003) Insulin resistance in nondiabetic morbidly obese patients: effect of bariatric surgery. Obes Res 11:1495-1501

6. Liang H, Ward WF (2006) PGC-1 $\alpha$ : a key regulator of energy metabolism. Adv Physiol Educ 30:145-151

7. Cartoni R, Leger B, Hock MB et al (2005) Mitofusins 1-2 and ERRalpha expression are increased in human skeletal muscle after physical exercise. J Physiol 567:349-358

8. Bach D, Pich S, Soriano FX et al (2003) Mitofusin-2 determines mitochondrial network architecture and mitochondrial metabolism. A novel regulatory mechanism altered in obesity. J Biol Chem 278:17190-17197
9. Pich S, Bach D, Briones P et al (2005) The Charcot-Marie-Tooth type 2A gene product, Mfn2, upregulates fuel oxidation through expression of OXPHOS system. Hum Mol Genet 14:1405-1415

10. Michael LF, Wu Z, Cheatham RB et al (2001) Restoration of insulin-sensitive glucose transporter (GLUT4) gene expression in muscle cells by the transcriptional coactivator PGC-1. Proc Natl Acad Sci USA 98:3820-3825

11. Patti ME, Butte AJ, Crunkhorn S et al (2003) Coordinated reduction of genes of oxidative metabolism in humans with insulin resistance and diabetes: Potential role of PGC1 and NRF1. Proc Natl Acad Sci USA 100:8466-8471

12. Bach D, Naon D, Pich S et al (2005) Expression of $M f n 2$, the Charcot-Marie-Tooth neuropathy type $2 \mathrm{~A}$ gene, in human skeletal muscle: effect of type 2 diabetes, obesity, weight loss, and the regulatory role of tumor necrosis factor alpha and interleukin-6. Diabetes 54:2685-2693

13. Russell AP, Hesselink MK, Lo SK, Schrauwen P (2005) Regulation of metabolic transcriptional co-activators and transcription factors with acute exercise. FASEB J 19:986-988

14. Holloszy JO (2005) Exercise-induced increase in muscle insulin sensitivity. J Appl Physiol 99:338-343

15. Song S, Zhang Y, Ma K et al (2004) Peroxisomal proliferator activated receptor gamma coactivator (PGC-1alpha) stimulates carnitine palmitoyltransferase 1 (CPT-1alpha) through the first intron. Biochim Biophys Acta 1679:164-173

16. Foster DW (2004) The role of the carnitine system in human metabolism. Ann N Y Acad Sci 1033:1-16

17. Kim JY, Hickner RC, Cortright RL, Dohm GL, Houmard JA (2000) Lipid oxidation is reduced in obese human skeletal muscle. Am J Physiol Endocrinol Metab 279:E1039-E1044

18. Simoneau JA, Veerkamp JH, Turcotte LP, Kelley DE (1999) Markers of capacity to utilize fatty acids in human skeletal muscle: relation to insulin resistance and obesity and effects of weight loss. FASEB J 13:2051-2060

19. Bobbioni-Harsch E, Morel P, Huber O et al (2000) Energy economy hampers body weight loss after gastric bypass. J Clin Endocrinol Metab 85:4695-4700

20. Samec S, Seydoux J, Dullo AG (1998) Role of UCP homologues in skeletal muscle and brown adipose tissue: mediators of thermogenesis or regulators of lipids as fuel substrate? FASEB J 12:715-724

21. Ricquier D (2005) Respiration uncoupling and metabolism in the control of energy expenditure. Proc Nutr Soc 64:47-52

22. Boss O, Bobbioni-Harsch E, Assimacopoulos-Jeannet F et al (1998) Uncoupling protein-3 expression in skeletal muscle and free fatty acids in obesity. Lancet 351:1933

23. Vidal-Puig A, Rosenbaum M, Considine RC, Leibel RL, Dohm GL, Lowell BB (1999) Effects of obesity and stable weight reduction on $U C P 2$ and $U C P 3$ gene expression in humans. Obes Res 7:133-140

24. Mingrone G, Rosa G, Greco AV et al (2003) Decreased uncoupling protein expression and intramyocytic triglyceride depletion in formerly obese subjects. Obes Res 11:632-640

25. Schrauwen P, Schaart G, Saris WH et al (2000) The effect of weight reduction on skeletal muscle UCP2 and UCP3 mRNA expression and UCP3 protein content in type II diabetic subjects. Diabetologia 43:1408-1416

26. Trostler N, Mann A, Zilberbush N, Avinoach E, Charuzi I (1995) Weight loss and food intake 18 months following vertical banded gastroplasty or gastric bypass for severe obesity. Obes Surg 51:39-51

27. Kendrick ML, Darkin GF (2006) Surgical approaches to obesity. Mayo Clin Proc 81:S18-S24

28. Segal KR, Van Loan M, Fitzgerald PI, Hodgdon JA, Van Itallie TB (1988) Lean body mass estimation by bioelectrical impedance analysis: a four-site cross-validation study. Am J Clin Nutr 47:7-14

29. Ferrannini E (1988) The theoretical bases of indirect calorimetry: a review. Metabolism 37:287-301 
30. Isaksson B (1980) Urinary nitrogen output as a validity test in dietary surveys. Am J Clin Nutr 33:4-5

31. DeFronzo RA, Tobin JD, Andres R (1979) Glucose clamp technique: a method for quantifying insulin secretion and resistance. Am J Physiol 237:E214-E223

32. Russell AP, Feilchenfeldt J, Schreiber S et al (2003) Endurance training in humans leads to fiber type-specific increases in levels of peroxisome proliferator-activated receptor-gamma coactivator-1 and peroxisome proliferator-activated receptor-alpha in skeletal muscle. Diabetes 52:2874-2881

33. Mingrone G, Manco M, Calvani M, Castagneto M, Naon D, Zorzano A (2005) Could the low level of expression of the gene encoding skeletal muscle mitofusin-2 account for the metabolic inflexibility of obesity? Diabetologia 48:2108-2114

34. Sugerman HJ, Kellum JM, Engle KM et al (1992) Gastric bypass for treating severe obesity. Am J Clin Nutr 55:560S-566S

35. Vazquez JA, Kazi U, Madani N (1995) Protein metabolism during weight reduction with very-low-energy diets: evaluation of the independent effect of protein and carbohydrate on protein sparing. Am J Clin Nutr 62:93-103

36. Goodpaster B, Wing RR, Simoneau JA (1999) Skeletal muscle fatty acid metabolism in association with insulin resistance, obesity, and weight loss. Am J Physiol 277:E1130-E1140
37. Zhang Y, Ma K, Song S, Elam MB, Cook GA, Park EA (2004) Peroxisomal proliferator-activated receptor-gamma coactivator-1 alpha (PGC-1 alpha) enhances the thyroid hormone induction of carnitine palmitoyltransferase 1 (CPT-1 alpha). J Biol Chem 279:53963-53971

38. Osburne RC, Meyers EA, Rodbard D, Burman KD, Georges LP, O'Brian JT (1983) Adaptation to hypocaloric feeding: physiologic significance of fall in serum T3 as measured by the pulse wave arrival time (QKd). Metabolism 32:9-13

39. Li L, Wu L, Wang C, Zhao Y (2007) Adiponectin modulates carnitine palmitoyltransferase-1 through AMPK signalling cascade in rat cardiomyocytes. Regul Pept 139:72-79

40. Kelley D, Goodpaster B, Wing R, Simoneau JA (1999) Skeletal muscle fatty acid metabolism in association with insulin resistance, obesity and weight loss. Am J Physiol 277:E1130-E1141

41. MacLellan JD, Gerrits MF, Gowing A, Smith PJ, Wheeler MB, Harper ME (2005) Physiological increases in uncoupling protein 3 augment fatty acid oxidation and decrease reactive oxygen species production without uncoupling respiration in muscle cell. Diabetes 54:2343-2350

42. Schrauwen P, Hoeks J, Schaart G et al (2003) Uncoupling protein 3 as a mitochondrial fatty acid anion exporter. FASEB J 17:22722274 